\title{
LARGAISSO: um quebra-cabeças formado com dispositivos móveis visando uma aproximação dos usuários
}

\author{
Mariana Burgarelli Santos ${ }^{1}$, Isabella Teixeira Martins ${ }^{1}$, Marcos F. Rodrigues ${ }^{1}$, \\ Suzana Cohen ${ }^{2}$, Elton José da Silva ${ }^{1}$ \\ ${ }^{1}$ Departamento de Computação - Universidade Federal de Ouro Preto (UFOP) \\ Caixa Postal n 38, CEP 35400-000 - Ouro Preto - MG - Brazil \\ ${ }^{2}$ Trends and Technology - Universidade de Lisboa \\ Lisboa - Portugal \\ marianaburgarelli@hotmail.com, isabella.tma@gmail.com, \\ marcos.rodriitgues@gmail.com, suzanacohen@gmail.com, ton.ufop@gmail.com
}

\begin{abstract}
Resumo. $O$ aplicativo proposto, LARGAISSO, busca a renovação das interações e uma aproximação das relações entre as pessoas. Trata-se da montagem colaborativa de quebra-cabeças utilizando os dispositivos móveis que visa a participação do grupo familiar e escolar. Para a elaboração do projeto, utilizou-se a metodologia de Design Sprint e de Design Centrado em Comunicação, dado o curto espaço de tempo de desenvolvimento e devido ao público alvo do aplicativo: crianças até 10 anos. Acredita-se que com o aplicativo as crianças se tornarão mais interessadas em jogos como quebracabeças, contribuindo para seu desenvolvimento cognitivo.
\end{abstract}

\section{Palavras-Chave}

Computação móvel; jogos digitais educativos, quebra-cabeças, design sprint, design centrado em comunicação.

\section{Cenário de uso}

A sociedade atual, vivenciando uma relação de quase imersão nas tecnologias, acaba por criar um isolamento entre as pessoas: cada um possui seu celular, tablet e computador e as interações tornaram-se distantes. Tornou-se raro famílias se divertindo com jogos de tabuleiro e outras brincadeiras.

O que se vê hoje são pessoas focadas em seus dispositivos eletrônicos, inclusive crianças, que cada vez mais cedo possuem acesso a este tipo de tecnologia.

"Os pais, para compensar certa ausência, deixam os filhos influenciarem as escolhas de compra da família, (...) etc". (Fonseca, 2004 apud Claro et al., 2012). Essa ausência acaba preenchida por bens materiais, como uma forma de compensação, sendo o celular um desses bens materiais fornecidos às crianças como forma de preencher a falta dos pais. Infelizmente, ao invés de agir como meio aproximador, por vezes, aumenta o distanciamento e torna as relações familiares superficiais.

Paiva e Costa (2015) afirmam que a tecnologia substitui hábitos tradicionais que envolvem a interação física entre as pessoas, apontando o uso indiscriminado como redutor do vínculo afetivo entre os membros de uma família e causador de problemas escolares dada a falta de equilíbrio entre os aspectos cognitivos e emocionais da criança. 
No entanto, é praticamente inviável querer impedir o acesso das crianças às tecnologias. $\mathrm{O}$ que se deve ter em mente é um equilíbrio, manter os limites saudáveis, seja para a criança, seja para as relações.

Buscamos uma solução que vai de encontro à isso. Nossa proposta visa inserir, de maneira saudável, a tecnologia no ambiente familiar e escolar, de modo a proporcionar uma experiência de interação real e única para as crianças. Dessa forma, acreditamos que um uso conjunto e supervisionado dos pais, responsáveis e professores seja o ideal.

A proposta de sua utilização dentro das escolas, busca incentivar a interação entre os alunos de todas as idades, em especial os recém alfabetizados. Como as crianças possuem acesso desde as mais tenras idades à tecnologia, é muito comum observar um certo desinteresse por atividades que não envolvam seu uso.

Frosi e Schlemmer (2010) apontam que os "nativos digitais" vivem e pensam com a tecnologia, a qual está sempre presente, tanto na comunicação quanto na maneira de se relacionarem com o mundo. Classificam os "nativos digitais" como parte da geração "Homo zappiens", definida como:

“[...] a nova geração que aprendeu a lidar com novas tecnologias, que cresceu usando múltiplos recursos tecnológicos desde a infância. Esses recursos permitiram ter controle sobre o fluxo de informações, mesclar comunidades virtuais e reais, comunicar-se e colaborar em rede, de acordo com suas necessidades. O Homo zappiens é um processador ativo de informação, resolve problemas de maneira muito hábil, usando estratégia de jogo, e sabe se comunicar muito bem. Sua relação com a escola mudou profundamente... o Homo zappiens é digital e a escola é analógica." (Veen \& Vrakking, 2009, p. 12, apud Frosi e Schlemmer, 2010)

Assim, é necessário que as escolas se adaptem à realidade dos alunos, fazendo com que o aprendizado que torne atrativo para os mesmos. Neste sentido, o aplicativo proposto $\left(\right.$ LARGAISSO $^{1}$ ) configura-se como uma uma maneira de captar o interesse das crianças em brincar de quebra-cabeças.

Adona e Vargas (2013) o quebra-cabeças como importante desenvolvedor "físico, neurológico, psicomotor, de capacidade de concentração, noção espacial, percepção visual e aumento de conhecimento sobre diversos assuntos". Neste sentido, o aplicativo possui grande aplicabilidade como uma ferramenta pedagógica auxiliar para o desenvolvimento das crianças de até 10 anos, podendo, inclusive, ser utilizado em aulas de educação artística, enriquecendo a qualidade de ensino e mobilizando o interesse das crianças, o que aumenta as perspectivas de aprendizado e desenvolvimento intelectual.

Além disso, quebra-cabeças tradicionais, considerando o uso infantil, possuem grande probabilidade de perda de peças e exigiria, inclusive, uma variedade de quebra-cabeças com diferentes número de peças ${ }^{2}$, o que configura em custo para as escolas. Sob este aspecto, o LARGAISSO não gera gastos para as escolas por se tratar de um aplicativo sem custos e com uma vasta opção de número de peças e jogadores.

\footnotetext{
1 Über Trends, www.ubertrends.com.br/tag/larga-isso/, acessado em 26/06/2017.

2 Segundo Adona e Vargas (2013), é "recomendado o gradual aumento do nível de dificuldade em cada jogo para estimular ainda mais o progresso da criança".
} 
VI Congresso Brasileiro de Informática na Educação (CBIE 2017)

Anais dos Workshops do VI Congresso Brasileiro de Informática na Educação (WCBIE 2017)

Não obstante, o LARGAISSO possui um set-up mais simples para preparar para brincar, não exigindo o desprendimento das peças e mesmo encaixes mais elaborados. Assim, propomos neste artigo o aplicativo LARGAISSO, descrito nas seções a seguir.

\section{Desenvolvimento}

O processo de criação do aplicativo seguiu as abordagens de Design Sprint ${ }^{3}$ (Sprint, 2017) desenvolvido pela Google Ventures, baseado em Design Thinking ${ }^{4}$ e Design Centrado em Comunicação, segundo os preceitos de Engenharia Semiótica ${ }^{5}$ aliadas à produção de diferentes tipos de artefatos.

Design Sprint $^{6}$ é um processo de design rápido onde um grupo de pessoas se reúne em poucos dias para encontrar soluções através de design, prototipagem e teste das ideias com os usuários.

O Design Sprint segue cinco etapas principais (Figura 1), a saber: (a) entedimento e definição do problema: procura-se entender as necessidades do usuário, do negócio e a tecnologia disponível, definindo estratégia e foco; (b) divergência e proposição de diferentes ideias (na perspectiva de que para se ter uma boa ideia é preciso ter várias), explorando o maior número de ideias, sempre com foco nas soluções; (c) decisão da melhor ideia através de votação: as ideias são refinadas e é escolhida a que será prototipada; (d) prototipação de média/alta fidelidade da solução pensada pelo time: criação de um protótipo para testar as ideias com os usuários, stakeholders e técnicos e (e) Validação do produto com usuários potenciais dando feedback real sobre a experiência de uso: apresentação do produto ao usuário, que interage e dá feedbacks.

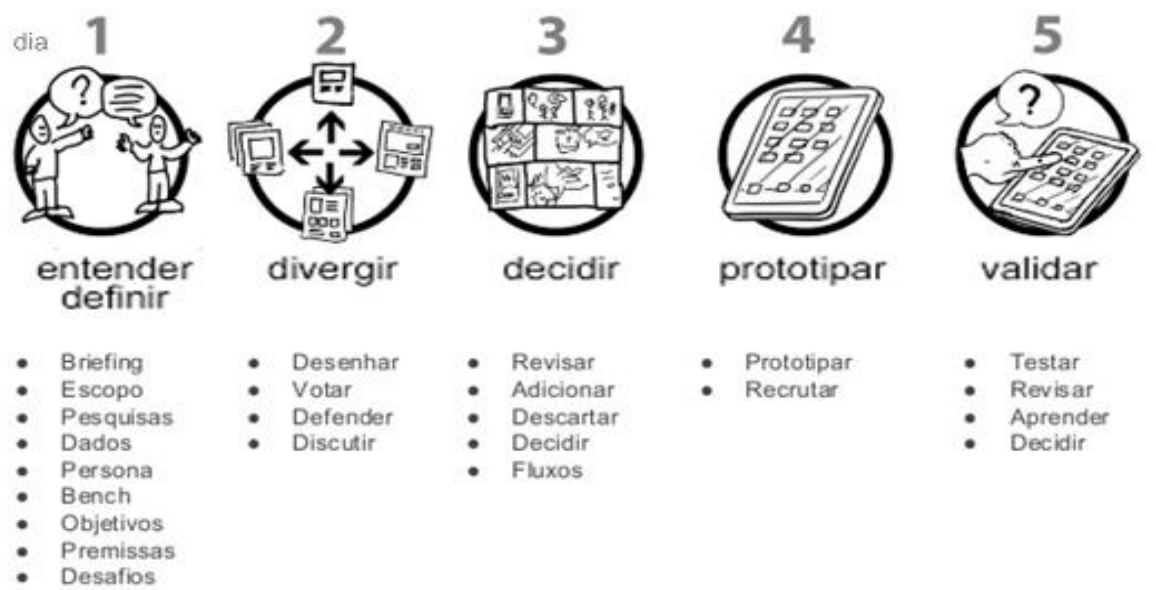

Figura 1. Etapas do Design Sprint ${ }^{7}$

\footnotetext{
3 Sprint, The Design Sprint, www.gv.com/sprint/, acessado em 01/07/2017.

4 Abordagem centrada no usuário que busca a inovação e resolução de problemas de forma coletiva (ideias diferentes, múltiplas perspectivas para criar algo inovador), com compreensão máxima dos seus stakeholders durante todo o desenvolvimento do produto. É uma ferramenta útil que aplica o pensamento criativo e crítico para compreender, visualizar e descrever problemas e, em seguida, desenvolver abordagens práticas para resolvê-los (BROWN, 2010).

${ }^{5}$ Segundo de Souza (2005a, apud Barbosa, 2010), a engenharia semiótica é uma teoria de IHC "centrada nos processos de significação e comunicação que envolvem designers, usuários e sistemas interativos”.

6 Uxdesign.cc Brasil. "Google Design Sprint: como funciona e como aplicar no seu projeto".https://brasil.uxdesign.cc/google-design-sprint-como-funciona-e-como-aplicar-no-seu-projeto279107363659 , acessado em 05/09/2017.
} 
VI Congresso Brasileiro de Informática na Educação (CBIE 2017)

Anais dos Workshops do VI Congresso Brasileiro de Informática na Educação (WCBIE 2017)

A escolha da metodologia participativa de solução de problemas Design Sprint foi devido a sua praticidade, rapidez, por se tratar de uma metodologia centrada no usuário, colaborativa e baseada em Design Thinking, que envolve a definição do problema e suas restrições, observação do público alvo em situações da vida real, geração de propostas, prototipação e testes e sustentabilidade.

Por ser um grupo composto por pessoas com diferentes backgrounds e um curto espaço de tempo para desenvolvimento do projeto, era necessário uma maneira eficaz de exposição de todas as diferentes ideias que surgiram e debate, assim o Design Sprint surgiu como uma alternativa mais que adequada.

O desenvolvimento do design partiu da observação das necessidades e dificuldades do grupo alvo, de forma a não gerar obstáculos aos usuários.

A opção pelo Design Centrado em Comunicação deu-se, principalmente devido ao public-alvo do aplicativo (crianças até 10 anos, mesmo que alfabetizadas, pais, responsáveis e educadores) faz-se necessária uma comunicação entre o aplicativo e usuário clara e de simples compreensão. O processo de Design Centrado em Comunicação se mostrou também adequado, pois norteia os esforços de design desde o início do processo pelas dúvidas que os usuários costumam ter durante a interação. Dessa forma, as soluções de IHC, em Design Centrado em Comunicação, são projetadas de forma a comunicar adequadamente informações necessárias para sanar dúvidas que possam surgir durante a interação (Barbosa, 2010).

Durante o processo de design, vários artefatos foram produzidos de modo a gerar um entendimento compartilhado para a equipe de desenvolvimento: personas\&objetivos, cenários de análise e interação, diagrama hierárquico de tarefas (Diagrama 1), diagrama de interação MoLIC - Modelling Language for Interaction as Conversation (Diagrama 2), protótipos em papel e protótipos de média/alta fidelidade utilizando a ferramenta Proto.io (https://proto.io/), sendo o processo de avaliação do aplicativo realizado com um grupo de cinco indivíduos. Não foi utilizada uma linguagem de programação específica, sendo o desenvolvimento dos mockups feito através da utilização de ferramentas.

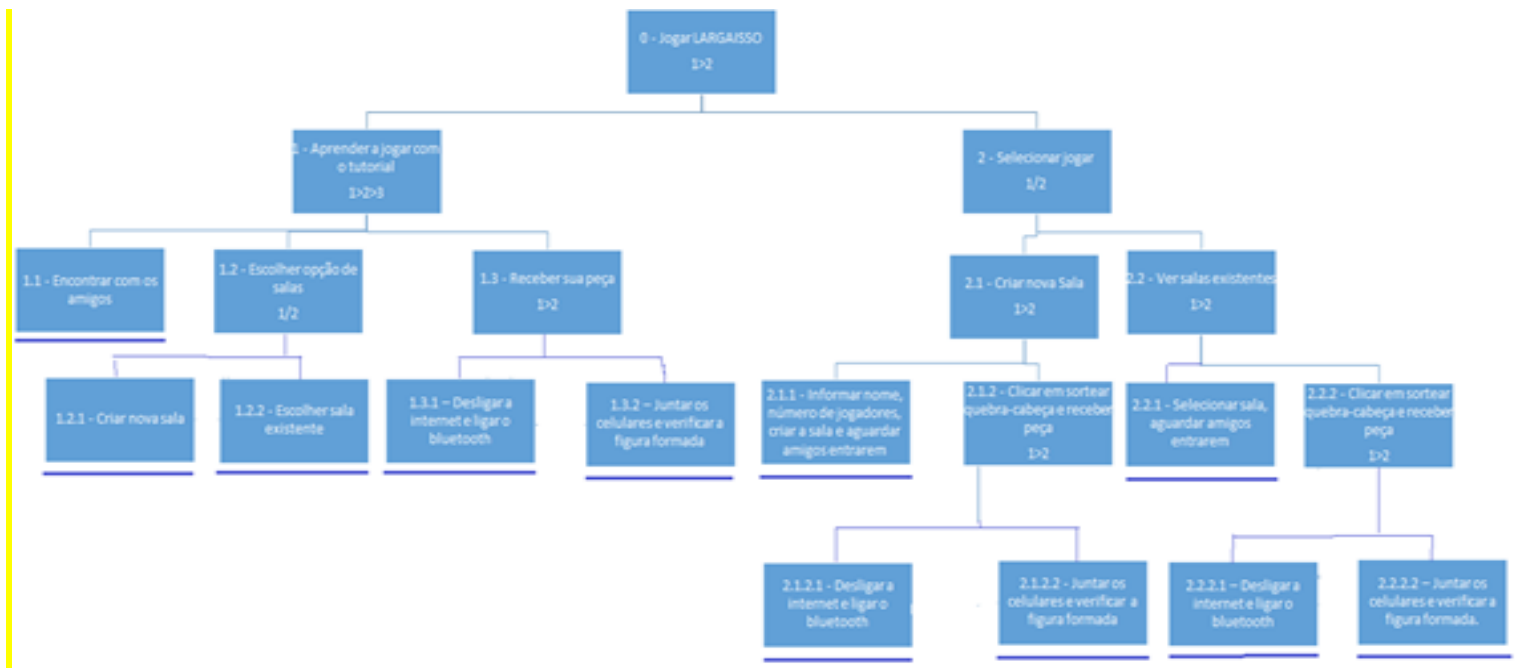

Diagrama 1. Diagrama Hierárquico de Tarefas do aplicativo LARGAISSO

${ }^{7}$ www.slideshare.net/huxleydias/um-ano-de-design-sprint-agilidade-colaboracao-e-aprendizados-huxleydias 
VI Congresso Brasileiro de Informática na Educação (CBIE 2017)

Anais dos Workshops do VI Congresso Brasileiro de Informática na Educação (WCBIE 2017)

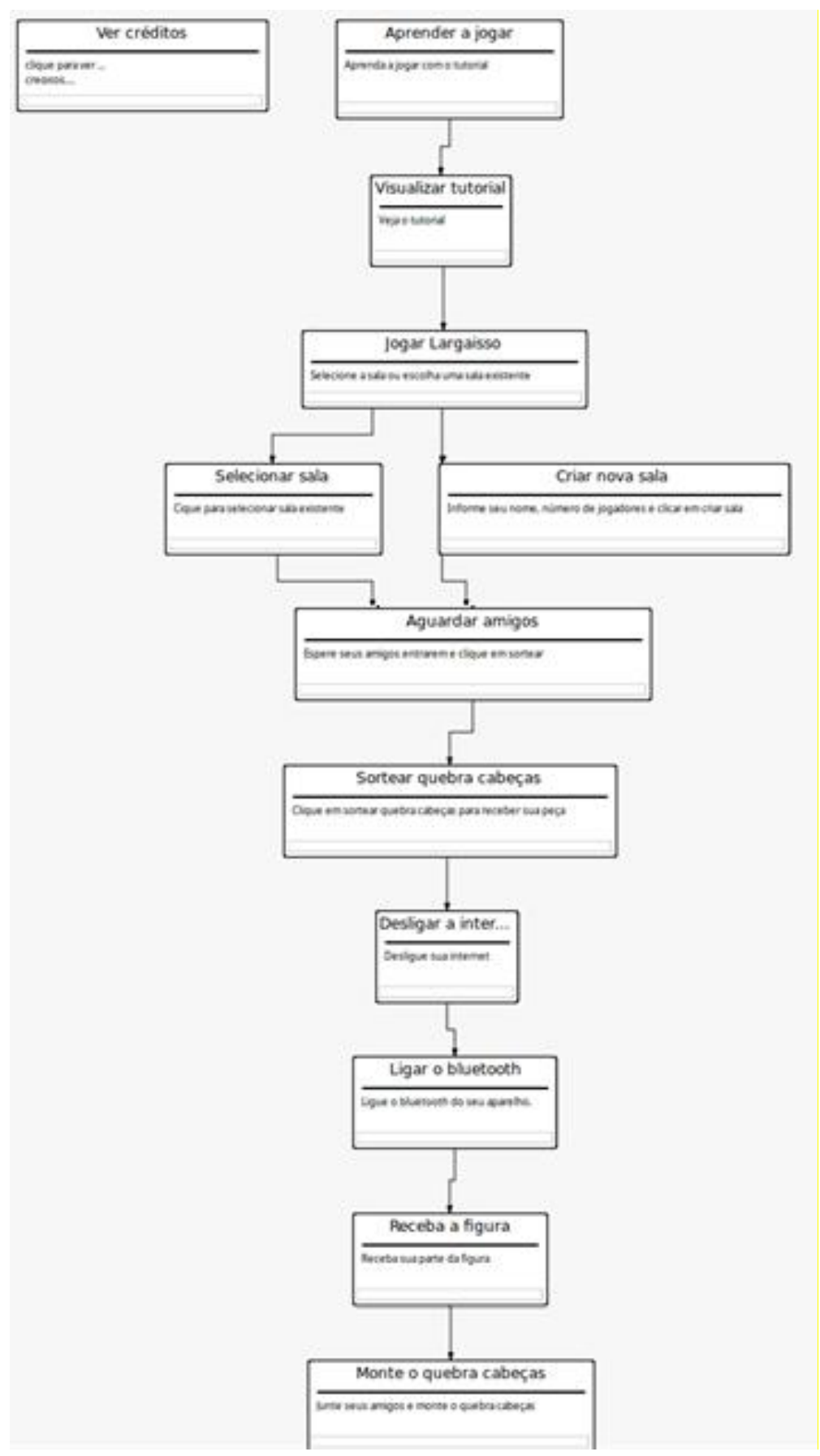

Diagrama 2. Trecho do Diagrama MoLIC

A importância da avaliação de interações e interfaces no processo de desenvolvimento de software reside no fato dos usuários poderem analisar informações objetivas e subjetivas no aplicativo, como a distribuição de textos, características dos botões e campos de formulário e comunicação do sistema com o usuário.

Para o aplicativo LARGAISSO, foi feita uma pesquisa de satisfação com 5 usuários de características e de gostos distintos, buscando obter uma avaliação o mais imparcial possível das peculiaridades do software (Tabela 1). 
VI Congresso Brasileiro de Informática na Educação (CBIE 2017)

Anais dos Workshops do VI Congresso Brasileiro de Informática na Educação (WCBIE 2017)

Tabela 1: Resposta dos usuários avaliados para o aplicativo LARGAISSO

\begin{tabular}{|c|c|c|c|c|}
\hline Idade & $\begin{array}{c}\text { Felicidade } \\
(0-10)\end{array}$ & $\begin{array}{c}\text { Diversão } \\
(0-10)\end{array}$ & $\begin{array}{c}\text { Aconselha } \\
(0-10)\end{array}$ & $\begin{array}{c}\text { Recomenda? } \\
\text { (Sim/Não })\end{array}$ \\
\hline 24 & 10 & 10 & 10 & Sim \\
\hline 22 & 9 & 10 & 10 & Sim \\
\hline 10 & 9 & 10 & 10 & Sim \\
\hline 8 & 10 & 10 & 10 & Sim \\
\hline 28 & 10 & 10 & 10 & \\
\hline
\end{tabular}

\section{Apresentação do Software}

O aplicativo tem sua justificativa pautada na necessidade de uma maior interação entre as crianças, seus pais e amigos, posto que com a constante inserção de tecnologias na sociedade as relações tornaram-se cada vez mais distantes. A proposta é utilizar a tecnologia buscando uma coletividade, um retorno das relações de proximidade, do brincar e se divertir ao lado da família e dos amigos, seja em casa ou na escola, de modo a tornar os jogos lúdicos mais interessantes para os "nativos digitais".

O LARGAISSO visa incentivar o uso da tecnologia de maneira saudável, incluindo crianças, educadores e responsáveis, de modo a resolverem quebra-cabeças juntos, retomando e reforçando as relações interpessoais e contribuindo para a cognição da criança.

Inicialmente, cada participante deve portar um dispositivo móvel, adquirir o aplicativo e instalar o mesmo. O projeto é que a distribuíção do aplicativo seja gratuita, facilitando o acesso a todas as escolas, famílias e alunos. O cadastro de jogadores é simples e intuitivo. A tela inicial do aplicativo é destacada na Figura 2.

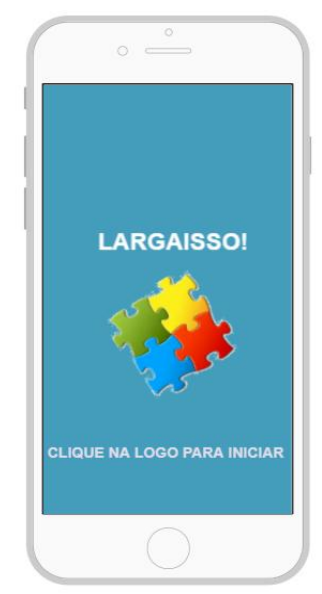

Figura 2. Tela inicial LARGAISSO 
VI Congresso Brasileiro de Informática na Educação (CBIE 2017)

Anais dos Workshops do VI Congresso Brasileiro de Informática na Educação (WCBIE 2017)

Para a montagem do quebra cabeças, os jogadores devem criar ou escolher uma sala virtual dependendo do número de participantes, conforme mostra a Figura 3.
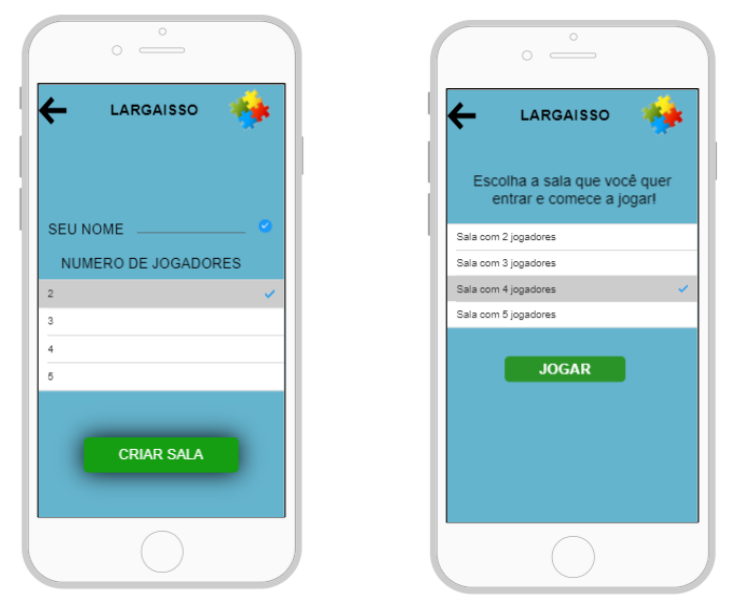

Figura 3. Criar nova sala e escolher sala existente

Feito isso, o jogo sorteia uma figura que deverá ser montada de acordo com o número de participantes e cada um recebe uma parte da figura do quebra cabeças, que deverá ser montada através da união dos dispositivos móveis.

Para a montagem, a internet dos celulares deve ser desligada (com vistas a proporcionar uma maior imersão no jogo em família, desligando o usuário do trabalho ou outras formas de distrações), e o bluetooth deve ser acionado, como ilustrado na Figura 4. Assim, ao unir os aparelhos, uma figura será formada.
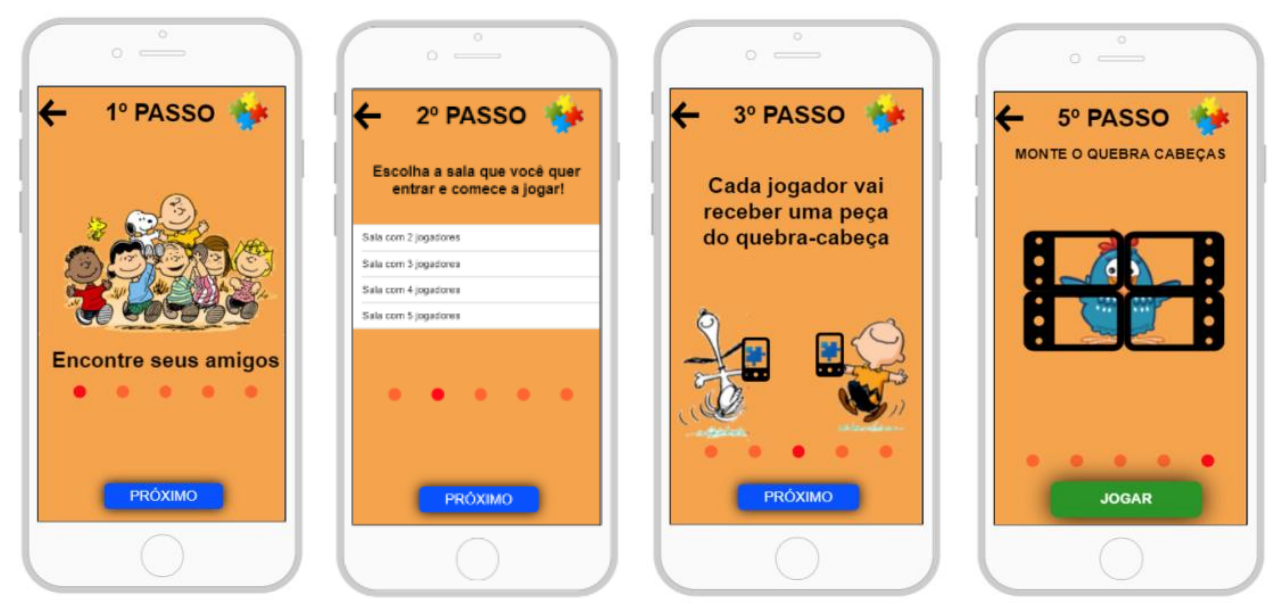

Figura 4. Exemplo de um quebra-cabeças simples

O link para o mockup interativo pode ser acessado em: https://share.proto.io/8RNOR8/

O link para o vídeo-demo apresentando a proposta do LARGAISSO pode ser acessado em: https://youtu.be/0FRHP95JFhQ. O vídeo foi produzido utilizando uma versão gratuita do aplicativo Filmora (https://filmora.wondershare.com.br/).

\section{Considerações finais}

A principal contribuição do aplicativo é a interação e fortalecimento das relações entre as crianças, seus amigos e pais/responsáveis/educadores através de dispositivos móveis, 
VI Congresso Brasileiro de Informática na Educação (CBIE 2017)

Anais dos Workshops do VI Congresso Brasileiro de Informática na Educação (WCBIE 2017)

posto que é inevitável o acesso das mesmas à tecnologia. Espera-se, assim, que o aplicativo seja mais uma ferramenta auxiliar no ensino e que colabore para o desenvolvimento intelectual e especial das crianças.

Do ponto de vista tecnológico, o aplicativo é viável, de acordo com as tecnologias utilizadas pelo mesmo (smartphone com tecnologia bluetooth).

Pelo fato de não haver necessidade de uma conexão via wifi ou internet móvel, o aplicativo pode ser usado em todos os lugares.

Do ponto de vista de compatibilidade, o aplicativo não necessita que os usuários possuam o mesmo modelo (ou marca) de smartphone, sendo o único pré-requisito o smartphone possuir a tecnologia bluetooth incorporada. $\mathrm{O}$ aplicativo poderá ser executado em smartphones Android, iOS e Windows, desde que suportem a tecnologia bluetooth.

No entanto, para que o aplicativo seja viável para todo e qualquer público, pode-se aprimorar meios de visualização da imagem, posto que as bordas dos aparelhos celulares e os diferentes tamanhos dos mesmos podem criar empecilhos à apresentação do quebra-cabeças, sendo este nosso próximo desafio como desenvolvedores. Na condição atual, propomos a utilização de modelos similares de celulares e, de preferência, com telas sem bordas laterais e bordas superior e inferior mínimas.

\section{Referências}

Adona, Claudia Piscinini, Vargas, Christine Lima. "O quebra-cabeça como possibilidade de ensino-aprendizagem na disciplina de educação física", 2013. Os desafios da escola pública paranaense na perspectiva do professor PDE - Artigos.

Barbosa, S. D. J., Silva, B. S. da, “Interação Humano-Computador”, Campus, 2010.

Brown, T. "Design thinking: uma metodologia poderosa para decretar o fim das velhas ideias", 2010. Rio de Janeiro: Elsiever.

Claro, J. A. C. S., Menconi, A. T. L., Loreto, J. R.. "Consumo infantil: o telefone celular e a criança", 2012.

Costa, J. da S., Paiva, M. N. M. de. "A influência da tecnologia na infância: desenvolvimento ou ameaça?", 2015. www.psicologia.pt/artigos/textos/A0839.pdf, acesso em 04/07/2017.

Frosi, Felipe O., Schlemmer, Eliane. "Jogos Digitais no Contexto Escolar: desafios e possibilidades para a Prática Docente”, 2010. Proceedings do SBGames 2010, Trilha de Games \& Cultura.

Sprint, The Design Sprint, www.gv.com/sprint/, acessado em 01/07/2017.

Über Trends, www.ubertrends.com.br/tag/larga-isso/, acessado em 26/06/2017.

Uxdesign.cc Brasil. "Google Design Sprint: como funciona e como aplicar no seu projeto".https://brasil.uxdesign.cc/google-design-sprint-como-funciona-e-comoaplicar-no-seu-projeto-279107363659, acessado em 05/09/2017. 